\title{
Recent developments in the WIPO Intergovernmental Committee on Intellectual Property and Genetic Resources, Traditional Knowledge and Folklore
}

\author{
Marcus Goffe
}

PhD Researcher, Queen Mary Intellectual Property Research Institute

At its Thirty-Eighth (19th Ordinary) Session held in Geneva, Switzerland from 22 September to 1 October 2009, the General Assembly of the World Intellectual Property Organization (WIPO) agreed to renew the mandate of the WIPO Intergovernmental Committee on Intellectual Property and Genetic Resources, Traditional Knowledge and Folklore (IGC) for the next budgetary biennium (2010/2011). ${ }^{1}$ Following much debate during the Fourteenth Session of the IGC as to the pace at which the work of the IGC was moving, the General Assembly specifically mandated the IGC to 'continue its work and undertake text-based negotiations with the objective of reaching agreement on a text of an international legal instrument (or instruments) which will ensure the effective protection of Genetic Resources (GRs), Traditional Knowledge (TK) and Expressions of Folklore/Traditional Cultural Expressions (TCEs)'.2

A clearly defined work programme for the 2010/2011 biennium was set out which, in addition to the 15th session of the Committee scheduled for December 2009, provided for four more sessions of the IGC and three intersessional working groups (IWGs) to be held in the 2010-2011 biennium. The 16th IGC decided that the IWGs 'shall provide legal and technical advice and analysis, including, where appropriate, options and scenarios for consideration of the IGC. The IWGs shall report to the IGC on the outcomes of their work and submit recommendations and texts relating to the discussion in the IGC.' 3

The First Intersessional Working Group (IWG1) commenced with much anticipation, ${ }^{4}$ as it was the first of the three Intersessionals organized to 'support and facilitate the negotiations of the IGC'. 5 WIPO working documents, specifically

1. <http://www.wipo.int/edocs/mdocs/tk/en/wipo_grtkf_ic_15/wipo_grtkf_ic_15_ref_ decision_28.pdf $>$.

2. <http://www.wipo.int/edocs/mdocs/tk/en/wipo_grtkf_ic_15/wipo_grtkf_ic_15_ref_ decision_28.pdf $>$.

3. <http://www.wipo.int/edocs/mdocs/tk/en/wipo_grtkf_ic_16/wipo_grtkf_ic_16_ref_ decision.pdf>.

4. K Mara, WIPO Traditional Knowledge Committee Agrees to Intensify Text-Based Negotiations, IP Watch, Online. Available: <http://www.ip-watch.org/weblog/2010/05/08/ wipo-traditional-knowledge-committee-agrees-to-intensify-text-based-negotiations/>.

5. <http://www.wipo.int/edocs/mdocs/tk/en/wipo_grtkf_ic_16/wipo_grtkf_ic_16_ref_ decision.pdf $>$. 
WIPO/GRTKF/IC/9/4, WIPO/GRTKF/IC/9/5 and WIPO/GRTKF/IC/11/8A, are to form the basis of the Committee's work on text-based negotiations. The order of the three Intersessionals was itself a much-debated issue at the 16th Session of the IGC.

Generally, the European Union and Group B countries wanted Traditional Knowledge to be debated and negotiated at the First Intersessional, presumably to precede the drafting of text for an international protocol on the same subject matter (traditional knowledge by the Convention on Biological Diversity (CBD)), in the context of access and benefit sharing of biological diversity, genetic resources and associated traditional knowledge. However, led largely by the African Group, the majority of member states at the 16th Session of the IGC decided that IWG1 would be on TCEs, with the subject matter of the other two intersessionals to be decided at the 17 th session of the IGC.

Other issues surrounding the Intersessionals which were debated at the Sixteenth IGC were the composition of the IWGs. Some states felt that to be most effective, the IWGs should not be open to all member states but only to a smaller group, perhaps regional representatives. Others felt that was too exclusionary and would not be representative enough. In the final analysis, it was decided that participation in the IWGs would be open to all member states and accredited observers, who would each be represented in plenary by one technical expert in his/her personal capacity. However additional representatives would still be able to attend and observe the proceedings by television in another room, but not in the plenary.

Document WIPO/GRTKF/IC/17/4 Prov. was used as the working document for IWG1. Early in IWG1, it was decided to allow group discussion of issues and articles for ease of process. Hence the plenary began to discuss the draft document articles in the following order: objectives and general guiding principles; subject matter of protection (Article 1); beneficiaries/management of rights (Articles 2 and 4); acts of misappropriation/exceptions and limitations/formalities (Articles 3, 5 and 7); term of protection/transitional measures (Articles 6 and 9); sanctions/remedies and exercise of rights (Article 8); relationship with IP protection and other forms of protection, preservation and promotion (Article 10); and, international and regional protection (Article 11).

However, by Tuesday afternoon the IWG1 in plenary had reached only 'Acts of Misappropriation/Exceptions and Limitations/Formalities' (Articles 3, 5 and 7) and the Chair of IWG1, Mrs Savitri Suwansathit from Thailand, announced that six informal, open-ended drafting groups would be formed the following day to work on drafting the several groups of articles, with drafting groups being open to all accredited experts. The informal drafting groups were to streamline text, and propose drafting options, if desirable, on each of the groups of issues.

\section{ARTICLE 1}

The Article 1 Drafting Group decided to limit the lists of protectable TCEs, as their view was that delegations kept on adding to the list, making it very unnecessarily unwieldy. Thus it was decided to outline the applicable criteria but to leave further detailed examples of protectable TCEs to national, sub-regional and regional levels. The agreed criteria, based on previous WIPO IGC Secretariat formulations, are:

'Traditional cultural expressions' and/or 'expressions of folklore' are any form, tangible or intangible, in which traditional culture [and knowledge] are embodied and have been passed on from generation to generation, including, but not limited to: 
(a) phonetic or verbal expressions, such as stories, epics, legends, poetry, riddles and other narratives; words, signs, names, and symbols;

(b) musical or sound expressions, such as songs, rhythms, and instrumental music;

(c) expressions by action, such as dances, plays, ceremonies, rituals, games, puppet performances, and other performances;

(d) tangible expressions, such as material expressions of art, handicrafts, architecture and spiritual forms.

\section{ARTICLES 2 AND 4}

In relation to Article 2, the main issue was how to classify the 'beneficiaries', specifically whether to specify 'indigenous', 'local', 'cultural' communities, and/or the state. However, it was generally agreed that at the international level, the text should be inclusive enough to allow for all variations and classifications of beneficiaries at the national level. The second issue with Article 2 was whether a criterion should be included that the TCEs be held in accordance with customary (community) laws and/or practices, or national laws and/or practices. The third issue in Article 2 was whether the TCEs must be 'characteristic' or 'unique' to a particular community. This was also relevant to the issue of whether protected TCEs (in Article 1) should be only those that are unique (as contemplated in Article 1 as drafted at the IWG1) or should also include TCEs that are shared or practised by more than one community.

Article 4 was more straightforward and there was generally more agreement on it. The consensus was that any management of TCEs rights must be authorized by and be done with the prior informed consent of the relevant community.

\section{ARTICLES 3, 5 AND 7}

Article 3 was a much more complex article. This was so because it sought to establish two levels of protection for two different categories of TCEs - secret and 'other protected' (non-secret). The rationale is that secret TCEs should have greater protection than non-secret TCEs. Article 3 also sought to address economic as well as moral rights. In the end, a drafting approach more consistent with conventional intellectual property legal construction was adopted. This included outlining the rights of fixation, reproduction, public performance, translation or adaptation, and making available or communicating to the public. However, the expert from Sweden did not agree with that formulation of rights, opting to draft alternative text requiring merely that the economic and moral interests of beneficiaries be safeguarded by national authorities 'in a reasonable and balanced manner'.

Interestingly, so as to strike some balance in the preferred absence of any registration formalities (Article 7), an exception to the exclusive rights of TCEs holders is proposed 'where the unauthorized user of a protected TCEs made a genuine good faith effort to locate the beneficiary ... and did not'. In those circumstances it is proposed that the beneficiary be entitled only to equitable remuneration or benefit sharing.

Article 5 on Exceptions and Limitations also produced very interesting and thought-provoking exchanges by experts in the informal drafting group. Again, the issue was how to balance the rights of beneficiaries with the rights of other users of TCEs. Generally, it was agreed that, rather than listing all the possible exceptions 
and limitations in the article, which may not be acceptable to all member states, the three-step test approach could be used to set a common standard, consistent with existing international and national intellectual property laws. This was not easy to agree, as many indigenous and local communities are sceptical about further subordinating their knowledge to the constructs and interpretations of intellectual property law. The three-step test is itself the subject of varying interpretations. It is not yet clear which of the three-step tests would be applicable - the one in the Berne Convention or its elaborations in the WIPO Copyright treaties and the TRIPS Agreement. Perhaps it is that ambiguity and therefore subjectivity that prompted the inclusion of the three-step test formulation in the draft text. It may also be an agreeable way for some states to feel comfortable with the codification of these new IPlike rights.

The Swedish expert wanted to ensure that archiving of TCEs, as well as derivative works and works inspired by TCEs, should not be subject to the TCEs rights of beneficiaries. He therefore opted to formulate an alternative clause which expressly preserved that exception. It was generally agreed that TCEs protection would not be applicable when the TCEs are used in traditional or customary contexts.

In relation to Formalities, the previous version of the WIPO Working Document on TCEs had proposed that secret TCEs should be registered in order to get protection. However, it was agreed that to require formalities may be inconsistent with the rights of TCEs holders and may be onerous and costly on many communities. Hence it was decided to remove the requirement for any formalities to receive protection. However, it was decided to retain language in the article that would encourage national authorities to consider maintaining voluntary registers or records of TCEs to aid prior art searches and the administration of rights.

\section{ARTICLES 6 AND 9}

Regarding Articles 6 and 9 (term of protection and transitional measures), there was surprisingly more consensus than one may have expected on the question of the indefinite term of protection for TCEs. The Director General of WIPO, Francis Gurry, is reported to have said that indefinite protection is not on the table. ${ }^{6}$ The Drafting Group prepared eight questions for discussion at the next IGC concerning whether the term of protection (Article 6) should be considered in relation to economic or moral rights, the public domain, individually or collectively held.

Article 9 addressing Transitional Measures also had alternative options and questions prepared by the drafting group. The first option was to state that continuing breaches of TCEs rights should be brought into conformity with the new provisions 'within a reasonable period of time after they enter into force'. It was argued that the rights of third parties, however, should be respected and maintained, save and except for those which have 'special significance' for the relevant communities. This issue of transitional measures and existing third party rights is understandably a very contentious one on which it will not be easy to achieve consensus.

6. K Mara, Perpetual Protection of Traditional Knowledge 'Not on Table' At WIPO, IPWatch, Online. Available: <http://www.ip-watch.org/weblog/2009/10/22/perpetual-protectionof-traditional-knowledge- $\%$ E2\% $80 \% 9$ Cnot-on-table\%E2\%80\%9D-at-wipo/>. 


\section{ARTICLE 8}

In relation to Sanctions/remedies and exercise of rights, the issue debated was whether and to what extent criminal, as opposed to just civil sanctions and remedies, ought to be available to TCEs rights holders. Several organizations representing indigenous and local communities wanted both civil and criminal remedies, as are available in respect of infringement of intellectual property rights. Some states wanted this to be left to national authorities to choose appropriate remedies, while others expressly wanted limits on the availability of criminal remedies, to cases of 'wilful misappropriation on a commercial scale'.

\section{ARTICLES 10 AND 11}

Article 10 (relationship to IP protection and other forms of protection, preservation and promotion) overlaps with third party rights under Article 9. The drafting group seemed to favour the complementarity of TCEs rights to intellectual property rights and the continuity of existing intellectual property rights. Article 11 (international and regional protection) was perhaps the least contentious article. It is generally agreed that national treatment would be fundamental to enforcing the rights and protection of TCEs internationally.

Experts at IWG1 also recommended that a set of definitions or glossary of key terms be prepared for consideration by the IGC, which could form the basis of a 'definitions' article within the text. The work of each of the informal drafting groups was consolidated and presented to all the experts in the IWG plenary subsequently. Both the Draft $\mathrm{Text}^{7}$ from the informal drafting groups as well as the comments from the plenary $^{8}$ were presented to the 17th IGC Session on 6-10 December 2010.

\section{THE 17TH IGC AND BEYOND}

At its 17th Session the IGC decided to take the draft text from IWG1 and to form another open-ended drafting group to streamline it by reducing the options and alternatives. The IGC mandated the current Chairperson, Ambassador Philip Owade of Kenya, to undertake informal consultations with all delegations to try to refine the text further, identify the key outstanding policy issues, and to prepare, if possible, a further draft of the articles (a Chair's text) for consideration by the 18th IGC set for May 2011. ${ }^{9}$

As recommended by IWG1 in its Summary Report (WIPO/GRTKF/IC/17/8), the IGC requested the Secretariat to prepare a glossary on intellectual property and TCEs for the 18th IGC session, as well as a glossary on intellectual property and traditional knowledge for IWG2. A glossary on intellectual property and genetic resources has already been prepared (WIPO/GRTKF/IC/17/INF/13).

7. Draft TCEs Text prepared at WIPO IWG1. Available: <http://www.wipo.int/edocs/mdocs/ tk/en/wipo_grtkf_iwg_1/wipo_grtkf_iwg_1_3.pdf>.

8. Record of Deliberations at IWG1. Available: <http://www.wipo.int/edocs/mdocs/tk/en/ wipo_grtkf_iwg_1/wipo_grtkf_iwg_1_4.pdf>.

9. WIPO, Decisions of the Seventeenth Session of the Committee, p. 3. Available: $<$ http://www.wipo.int/edocs/mdocs/tk/en/wipo_grtkf_ic_17/wipo_grtkf_ic_17_ref_decisions. doc $>$. 
The IGC also reviewed the draft articles on TK produced by the WIPO Secretariat over many sessions ago, which have been continually reviewed and revised, and transmitted them for consideration at IWG2.

The WIPO Secretariat continues to produce seminal research and publications of utmost importance to the IGC process. By facilitating open and balanced discussion and exchange over the years, involving a wide cross-section of not only member states but also indigenous and local communities, academics and industry representatives, WIPO continues to play an invaluable role in advancing this area of law and policy. Whenever and wherever substantive legal and procedural issues arise, the Secretariat at WIPO has responded to requests for it to furnish additional research, as well as legal and policy options and alternatives.

The Working Documents (Revised Objectives and Principles) produced by the WIPO Secretariat on TCEs and TK are the basis of the IGC and IWG deliberations and negotiations whereas a Revised List of Options and Factual Update is the basis for negotiations on genetic resources. The Secretariat recently prepared for the 17th IGC session WIPO/GRTKF/IC/17/INF/12 ('Genetic Resources: Draft Intellectual Property Guidelines for Access and Equitable Benefit-Sharing: Updated Version). As requested specifically at the 16th IGC, the Secretariat also prepared for the 17th IGC a list and brief technical explanation of various forms in which traditional knowledge may be found (WIPO/GRTKF/IC/17/INF/9), ${ }^{10}$ as well as a technical information document (WIPO/GRTKF/IC/17/INF/8) on the meanings of the term 'public domain' in the intellectual property system, with special reference to the protection of traditional knowledge and traditional cultural expressions. ${ }^{11}$

Document WIPO/GRTKF/IC/17/INF/9 details as far as possible the several working definitions of TK as well as various categories, some overlapping, in which TK may be found. The categories listed are:

- unfixed TK and fixed TK, to which are related: (a) documented TK and nondocumented TK and (b) codified TK and non-codified TK;

- disclosed TK and non-disclosed TK, to which are related: (a) TK directly controlled by indigenous and local communities and TK no longer in the control of indigenous and local communities and (b) TK held by indigenous and local communities;

- sacred TK and secular TK;

- TK 'as such' and TK-based innovations and creations;

- indigenous knowledge and traditional knowledge;

- individual TK and collective TK; and,

- commercialized TK and non-commercialized TK.

Document WIPO/GRTKF/IC/17/INF/8 analyses the public domain in relation to copyright, trademarks, patents, trade secrets, as well as in relation to the common heritage of mankind, res nullius, the commons, and prior art. It discusses a 'domaine public payante' or compulsory licence/user fee option. Interestingly, while that document recognizes that there are several different and sometimes overlapping definitions of public domain, it recognizes that in relation to TK there is a critical distinction between TK associated with genetic resources being in the 'public domain' and that

10. <http://www.wipo.int/edocs/mdocs/sct/en/wipo_grtkf_ic_17/wipo_grtkf_ic_17_inf_9. doc>.

11. <http://www.wipo.int/edocs/mdocs/tk/en/wipo_grtkf_ic_17/wipo_grtkf_ic_17_inf_8. doc>. 
TK that has been made 'publicly available'. While making a significant contribution to the development of policy, nevertheless the document is necessarily consistent with WIPO's limited political mandate to advance solutions and so does not propose workable recommendations to achieve the balance between the western intellectual property and indigenous customary perspectives on rights and the public domain.

Not only has the IGC allowed indigenous and local community representatives to be accredited observers at the IGC, to speak and be heard in plenary during the IGC sessions, but also since the seventh session, the Panel of Indigenous and Local Communities has been established to allow indigenous and local community representatives to raise and elucidate their grievances and issues of concern for consideration by the IGC before the commencement of each IGC session. However, over time, the panel presentations have been poorly attended by member states and other accredited observers as the negotiations became more intense and the IGC entered the treaty drafting stage.

The IGC has recently responded to this perceived inadequacy of the Panel by refocusing each Panel on a specific issue or item that is being debated in the IGC. Thus at the 16th IGC the Panel focused on prior informed consent and saw several indigenous and non-governmental representatives sharing their views on the meaning and import of prior informed consent. At the recently concluded 17th session, the Panel focused on the public domain, another issue which has received much debate within the IGC. The panellists were from several communities in Canada, Indonesia, Nigeria and Russia, and presented on their particular community's perceptions and experiences with the concept of the public domain. The IGC has thus managed to maintain the effectiveness of the Panel by allowing indigenous and community representatives and perspectives to influence the discussions and decisions of the IGC including the drafting of treaty text.

Analyses of the gaps between conventional intellectual property laws and community customary laws have been prepared. In 2006 WIPO published an Issues Paper entirely on customary law intended to address some lingering concerns regarding interoperability of the two regimes. ${ }^{12}$ The most recent WIPO publication on the protection of TCEs is the December 2010 paper on 'Intellectual Property and the Safeguarding of Traditional Cultures: Legal Issues and Practical Options for Museums, Libraries and Archives' ${ }^{13}$

At its 16th Session, the IGC also requested the WIPO Secretariat to update the WIPO Database of Biodiversity-related Access and Benefit-sharing Agreements. ${ }^{14}$ The Secretariat started that process by circulating a 'Questionnaire on Contractual Practices and Clauses relating to Intellectual Property, Access to Genetic Resources and Benefit-Sharing' 15 to member states and observers. The stated aim of the database is 'to provide information resources for those seeking assistance on current practices relating to IP, access and benefit sharing and genetic resources' and 'to contribute to

12. WIPO, Customary Law \& the Intellectual Property System in the Protection of Traditional Cultural Expressions and Traditional Knowledge Issues Paper - Version 3.0 (December 2006), Available: <http://www.wipo.int/export/sites/www/tk/en/consultations/customary_law/issuesrevised.pdf $>$.

13. Written for WIPO by M Torsen and J Anderson, <http://www.wipo.int/export/sites/www/ tk/en/publications/1023.pdf $>$. This paper was written for WIPO by Molly Torsen and Jane Anderson.

14. <http://www.wipo.int/tk/en/databases/contracts/search/index.html>.

15. <http://www.wipo.int/tk/en/databases/contracts/index.html>. 
the development of the WIPO Intellectual Property Guidelines for Access and Equitable Benefit-sharing'. ${ }^{16}$ The database contains several different types of biodiversity-related access and benefit-sharing agreements, including material transfer agreements, research agreements, licensing agreements, as well as intellectual property agreements and clauses, including those with prior informed consent and benefitsharing provisions.

In relation to access and benefit sharing in respect of genetic resources and associated traditional knowledge, the precarious relationship between developments in WIPO and in the CBD continue to take centre stage. Recently this has been no more evident than with the passage in October 2010 of the Nagoya Protocol on Access to Genetic Resources and the Fair and Equitable Sharing of Benefits Arising from their Utilization. As seen earlier in the IGC, regarding the selection of topics to be considered by the IWGs, negotiators and representatives in both forums are very aware of the two fronts on which this battle of genetic resources and traditional knowledge (state sovereignty vs community rights) is being fought.

According to the CBD Press Release, '[t]he historic agreement creates a framework that balances access to genetic resources on the basis of prior informed consent and mutually agreed terms with the fair and equitable sharing of benefits while taking into account the important role of traditional knowledge. The Protocol also proposes the creation of a global multilateral mechanism that will operate in transboundary areas or situations where prior informed consent cannot be obtained. ${ }^{17}$ Consistent with the CBD and the Bonn Guidelines, the Nagoya Protocol stipulates that countries which benefit from the use of genetic resources and associated traditional knowledge shall share such benefits equitably with the country or community of origin. The Protocol requires member states to take legislative, administrative or policy measures to ensure equitable benefit sharing.

Although hailed as a landmark international instrument, the Protocol has been criticized by several indigenous representatives as being too weak in regard to the rights of communities, ${ }^{18}$ particularly because the rights of indigenous and local communities are to be interpreted according to domestic legislation. ${ }^{19}$ Similarly, prior informed consent, effective participation of indigenous and local communities, and consideration for their customary laws is subject to domestic law. Nevertheless, it is seen as further codifying, crystallizing and enforcing these important principles in international law. Thus it should come as no surprise that as soon as the Nagoya Protocol was passed than negotiators in the IGC sought to capitalize upon it.

At the 17th IGC in December, in response to a submission by the delegations of Australia, Canada, Japan, Norway, New Zealand and the United States of America in relation to agenda item 'genetic resources', the African Group submitted a proposal in which it emphasized that the "[w]ork of the IGC should be mutually supportive of the CBD and the Nagoya Protocol and it should not run counter to the objectives of the

16. <http://www.wipo.int/edocs/mdocs/tk/en/wipo_grtkf_ic_17/wipo_grtkf_ic_17_inf_11. doc>.

17. <http://www.cbd.int/doc/press/2010/pr-2010-10-29-cop-10-en.pdf>.

18. Saez, Compromise UN Protocol Treaty Against Biopiracy Adopted in Japan, Intellectual Property Watch, 29 October 2010, Available: <http://www.ip-watch.org/weblog/2010/10/29/ compromise-un-protocol-treaty-against-biopiracy-adopted-in-japan/?utm_source=post\&utm_ medium $=$ email\&utm_campaign=alerts $>$.

19. Article 4 Nagoya Protocol, <http://www.cbd.int/cop/cop-10/doc/advance-final-uneditedtexts/advance-unedited-version-ABS-Protocol-footnote-en.doc $>$. 
CBD and the Nagoya Protocol'. ${ }^{20}$ The African Group's position is that a mandatory disclosure requirement should be the basis for the negotiations on Genetic Resources in the IGC. In that respect, the African Group has supported the proposals by Switzerland made at the 11th IGC in 2007 (Document WIPO/GRTKF/IC/11/10) to amend the Patent Cooperation Treaty and the Patent Law Treaty to require a mandatory disclosure requirement of the origin of the genetic resource, ${ }^{21}$ which would be enforced by incorporation of the 'internationally recognized certificate of compliance' as stipulated in the Nagoya Protocol. The African Group has also supported the proposals by the EU made at the eighth session of the IGC in 2005 (Document WIPO/GRTKF/IC/8/11) in relation to there being a mandatory requirement of disclosure of origin or source of genetic resources and traditional knowledge in all patent applications. $^{22}$ These issues are certain to be debated strongly at IWG2 and IWG3.

IWG2 on Traditional Knowledge is scheduled for 21-25 February 2011 and IWG3 on Genetic Resources is scheduled for 28 February to 4 March 2011. The next (18th) Session of the IGC is scheduled for 9-13 May 2011 in Geneva.

20. Document WIPO/GRTKF/IC/17/10, <http://www.wipo.int/edocs/mdocs/tk/en/wipo_ grtkf_ic_17/wipo_grtkf_ic_17_10.doc>.

21. <http://www.wipo.int/edocs/mdocs/tk/en/wipo_grtkf_iwg_3/wipo_grtkf_iwg_3_8.doc>.

22. <http://www.wipo.int/edocs/mdocs/tk/en/wipo_grtkf_iwg_3/wipo_grtkf_iwg_3_2.doc> 